\title{
Sistem Respon Satu Derajat Kebebasan terhadap Beban Harmonik pada Struktur Portal 2D
}

\author{
Indah Melati Suci ${ }^{1}$, Astika Rajmi ${ }^{1}$, Andi Muhammad Alfian Arafat ${ }^{1}$, \\ Muhammad Zubair Muis Alie ${ }^{1 *}$ \\ ${ }^{1}$ Departemen Teknik Kelautan, Fakultas Teknik, Universitas Hasanuddin \\ Jl. Poros Malino km. 6, Bontomarannu, Kabupaten Gowa, Sulawesi Selatan 92171 \\ *Email: zubair.m@eng.unhas.ac.id
}

DOI: 10.25042/jpe.112019.07

\begin{abstract}
Abstrak
System respon satu derajat kebebasan terhadap beban harmonik pada struktur yang diidealkan sebagai sistem kebebasantingkat-unggal yang tereksitasi secara harmonis yaitu struktur yang terkena beban atau perpindahan yang besarnya dapat diwakili oleh fungsi sinus atau kosinus waktu. Jenis eksitasi ini menghasilkan salah satu gerakan paling penting dalam studi getaran mekanik serta aplikasi untuk dinamika struktur. Struktur sangat sering mengalami aksi dinamis seperti beban siklus yang bekerja dan menghasilkan respon karena keberadaan eksentrisitas massa yang tak terhindarkan. Penelitian ini bertujuan untuk menganalisis system respon derajat tunggal terhadap beban harmonic pada struktur portal dua-dimensi (2D). Portal dimodelkan dan dianalisis dengan menggunakan metode elemen hingga. Hasil yang diperoleh adalah perpindahan titik dari struktur.
\end{abstract}

\begin{abstract}
One Degree Freedom Response System to Harmonic Loads in 2D Portal Structure. Response of one degree of freedom system to harmonic loading on the structure idealized as single degree of freedom systems excited harmonically, that is structure subjected to force or displacement where the magnitude may be represented by a sine or cosine function of time. This type of excitation results one of the most important motions in the study of mechanical vibrations as well as in applications to structural dynamics. Structure is very often subjected to the dynamic action such cyclic load acting and resulting response due to the the unavoidable load eccentricity. The objective of the present study is to analyze the response of one-degree of freedom system to the portal 2D. The structure is modelled and analyzed using finite element method. The result obtained by FE method is joint displacement of the structure.
\end{abstract}

Kata Kunci: Beban harmonik, FEM-SAP, portal 2D, sistem derajat kebebasan

\section{Pendahuluan}

Portal merupakan salah struktur yang banyak dijumpai. Portal terdiri dari elemen-elemen balok dan kolom. Elemen-elemen balok dan kolom tersebut terhubung secara kaku pada satu titik. Titik ini disebut sambungan kaku (Rigid Joint). Umumnya sistem struktur portal digunakan bila beban gravitasi lebih dominan dari pada beban lateral akibat gaya gempa dan angin. Sistem struktur portal identik dengan struktur rangka yang mana juga terdiri dari elemen-elemen balok dan kolom yang saling terhubung pada sambungan yang kaku.

Penelitian yang terkait dengan analisis struktur portal dan rangka diantaranya adalah Muis Alie dkk. [1] menganalisis kekuatan batas struktur jacket platform dengan mempertibangkan konfigurasi elemen brace dan kolom. Analisis tekuk dan umur lelah dari struktur jacket yang simetris dan tidak simetris dilakukan oleh Muis Alie [2]. Aeran dkk. [3] mengusulkan kerangka kerja untuk keberlangsungan umur dari struktur jacket offshore. Formulasi baru untuk analisis struktur guyed tower dimana tiangnya dimodel sebagai balok-kolom ekivalen pada tumpuan elastik nonlinear oleh Paez dan Sensale [4]. Shi dan Salim [5] menginvestigasi respon nonlinear guyed tower dari beban statik dan dinamik dengan menggunakan metode FEM. Metode optimasi perancangan struktur yang dikembangkan berdasarkan teori optimasi topologi dilakukan oleh Tian dkk. [6]. Vaz dkk. [7] memaparkan percobaan dan model FE untuk memperoleh kekuatan batas struktur tubular dengan lubang kerusakan yang terjadi secara melingkar terhadap beban tekan aksial. 


\section{Teori Dasar}

Sistem derajat kebebasan tunggal (SDOF) hanya mempunyai satu koordinat yang diperlukan untuk menyatakan posisi massa pada saat tertentu yang ditinjau. Bangunan satu tingkat adalah salah satu contoh bangunan derajat kebabasan tunggal. Sistem tersebut dapat dilihat pada Gambar 1.

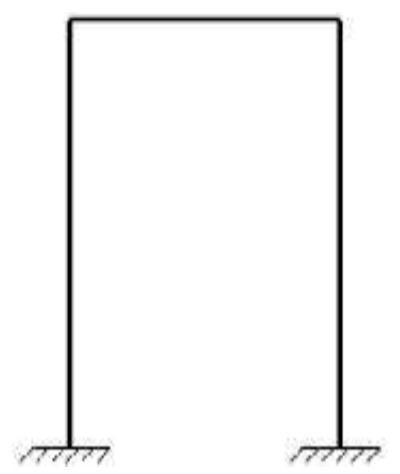

Gambar 1. Model struktur

Gaya $\mathrm{F}(\mathrm{t})$ yang bekerja pada osilator sederhana pada Gambar 2 diasumsikan harmonic dan sama dengan $F_{o} \sin \omega t$, dimana $F_{0}$ adalah amplitude puncak dan $\mathrm{w}$ adalah frekuensi gaya dalam radian perdetik.

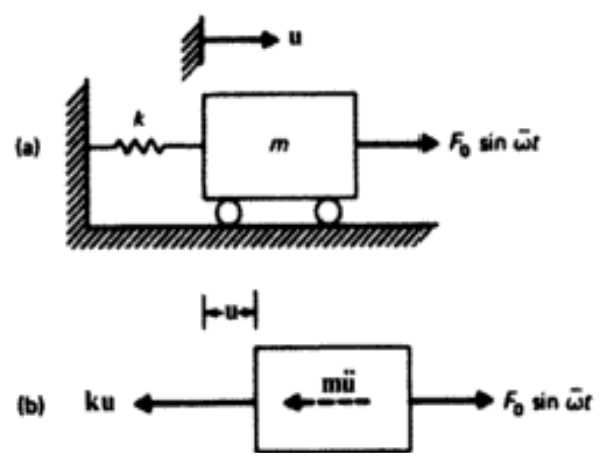

Gambar 2. (a) Osilator terbuka yang secara harmonis tereksitasi. (b) diagram benda bebas

Persamaan diferensial diperoleh dengan menjumlahkan semua gaya dalam diagram benda bebas dari Gambar 2 (b) yaitu:

$$
m u+k u=F o \sin \omega t
$$

Solusi Persamaan (1) dapat dinyatakan sebagai:

$$
u(t)=u_{c}(t)+u_{p}(t)
$$

dimana $u_{c}(t)$ solusi komplementer memenuhi persamaan homogen yaitu Persamaan (1) dengan mengatur ruas kiri sama dengan nol; dan $u_{p}(t)$ merupakan solusi khusus yang didasarkan pada solusi yang memenuhi persamaan diferensial non homogen (1). Solusi komplementer $u_{c}(t)$ diberikan sebagai:

$$
u_{c}(t)=A \cos \omega t+B \sin \omega t
$$

dimana:

$$
\omega=\sqrt{k / m}
$$

Sifat fungsi getaran paksa dalam Persamaan (1) menunjukkan bahwa solusi khusus diambil sebagai:

$$
u_{p}(t)=U \sin \omega t
$$

dimana U adalah amplitudo dari solusi khusus. Substitusi Persamaan (4) ke Persamaan (1) sehingga diperoleh faktor-faktor umum:

$$
-m \omega^{2} U+k U=F_{o}
$$

\section{Hasil dan Pembahasan}

Rangka baja yang ditunjukkan pada Gambar 3 mendukung mesin berputar yang memberikan gaya horizontal pada tingkat gelagar $\mathrm{F}(\mathrm{t})=200$ sin 5.3t (lb). Asumsikan 5\% redaman kritis dan tentukan: (a) amplitudo kondisi-mapan getaran, dan (b) tekanan dinamis maksimum dalam kolom. Anggap gelagar itu kaku.

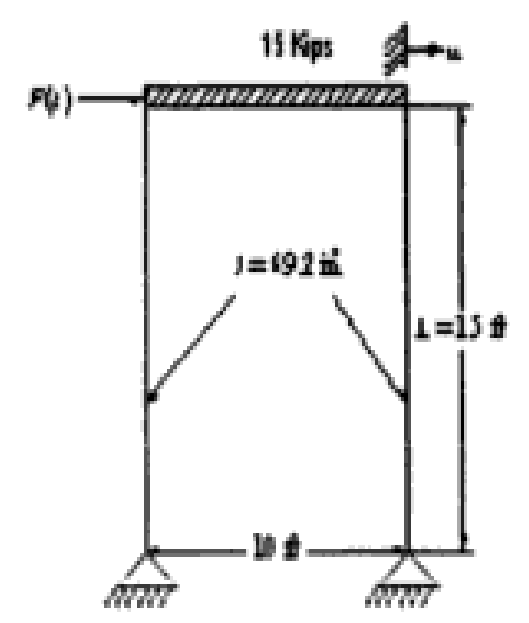

Gambar 3. Model analisis 
Penyelesaian:

Parameter untuk struktur di atas yaitu:

- Mass : $m=38.86\left(l b \cdot \frac{\sec ^{2}}{i n}\right)$

- Damping : $\xi=0.05$

- Amplitude Harmonic Force : $F_{o}=200(l b)$

- Force Time Function : $F_{t}=\sin 5.3 t$

- Periode : $5.3 \mathrm{t}=2 \pi, T=1.1855 \mathrm{sec}$

- Time Step: $\Delta t=\frac{T}{20}=0.059275 \mathrm{sec}$

Tabel 1 adalah fungsi harmonik dimana aksi yang dihasilkan merupakan fungsi dari waktu. Tabel 2 dan Tabel 3 menggambarkan perpindahan titik dan gaya elemen-elemen yang terdapat pada struktur.
Table 1. Fungsi harmonik

\begin{tabular}{cc}
\hline $\mathbf{t}(\mathbf{s e c})$ & $\mathbf{F}(\mathbf{t})=\sin \mathbf{5 . 3 t}$ \\
\hline 0 & 0 \\
0.0593 & 0.3090 \\
0.1186 & 0.5878 \\
0.1778 & 0.8090 \\
0.2371 & 0.9511 \\
0.2964 & 1 \\
0.3557 & 0.9511 \\
0.4149 & 0.8090 \\
0.4742 & 0.5878 \\
0.5335 & 0.3090 \\
0.5928 & 0 \\
0.6520 & -0.3090 \\
0.7113 & -0.5878 \\
0.7706 & -0.8090 \\
0.8299 & -0.9511 \\
0.8891 & -1 \\
0.9484 & -0.9511 \\
1.0077 & -0.8090 \\
1.0670 & -0.5978 \\
1.1262 & -0.3090 \\
1.1855 & 0 \\
&
\end{tabular}

Tabel 2. Joint displacements

\begin{tabular}{cccccccccc}
\hline Joint & OutputCase & Case Type & Step Type & $\begin{array}{c}\text { U1 } \\
\text { in }\end{array}$ & $\begin{array}{c}\text { U2 } \\
\text { in }\end{array}$ & $\begin{array}{c}\text { U3 } \\
\text { in }\end{array}$ & $\begin{array}{c}\text { R1 } \\
\text { Rad }\end{array}$ & $\begin{array}{c}\text { R2 } \\
\text { Rad }\end{array}$ & $\begin{array}{c}\text { R3 } \\
\text { Rad }\end{array}$ \\
\hline 1 & HIST1 & LinModHist & Maks & 0. & 0. & 0. & 0. & $4.828 \times 10^{-6}$ & 0. \\
1 & HIST1 & LinModHist & Min & 0. & 0. & 0. & 0. & $-4.833 \times 10^{-6}$ & 0. \\
2 & HIST1 & LinModHist & Maks & 0,000579 & 0. & 0. & 0. & $7.424 \times 10^{-11}$ & 0. \\
2 & HIST1 & LinModHist & Min & -0.00058 & 0. & 0. & 0. & $-7.431 \times 10^{-11}$ & 0. \\
3 & HIST1 & LinModHist & Maks & 0. & 0. & 0. & 0. & $4.828 \times 10^{-6}$ & 0. \\
3 & HIST1 & LinModHist & Min & 0. & 0. & 0. & 0. & $-4.833 \times 10^{-6}$ & 0. \\
4 & HIST1 & LinModHist & Maks & 0,000579 & 0. & 0. & 0. & $7.424 \times 10^{-11}$ & 0. \\
4 & HIST1 & LinModHist & Min & -0.00058 & 0. & 0. & 0. & $-7.431 \times 10^{-11}$ & 0. \\
\hline
\end{tabular}

Tabel 3. Frame element forces

\begin{tabular}{cccccccccccc}
\hline Frame & $\begin{array}{c}\text { Station } \\
\text { in }\end{array}$ & $\begin{array}{c}\text { Output } \\
\text { Case }\end{array}$ & $\begin{array}{c}\text { Step } \\
\text { Type }\end{array}$ & $\begin{array}{c}\mathbf{P} \\
\mathbf{L b}\end{array}$ & $\begin{array}{c}\mathbf{V 2} \\
\mathbf{L b}\end{array}$ & $\begin{array}{c}\mathbf{V 3} \\
\mathbf{L b}\end{array}$ & $\mathbf{T}$ & $\begin{array}{c}\text { M2 } \\
\text { Lb-in }\end{array}$ & $\begin{array}{c}\text { M3 } \\
\text { Lb-in }\end{array}$ & $\begin{array}{c}\text { Frame } \\
\text { Elemen }\end{array}$ & $\begin{array}{c}\text { Elem } \\
\text { Station } \\
\text { in }\end{array}$ \\
\hline 1 & 0. & HIST1 & Max & 0. & 97.69 & 0. & 0. & 0. & $6.684 \times 10^{-12}$ & $1-1$ & 0. \\
1 & 90. & HIST1 & Max & 0. & 97.69 & 0. & 0. & 0. & 8800.75 & $1-1$ & 90. \\
1 & 180. & HIST1 & Max & 0. & 97.69 & 0. & 0. & 0. & 17601.5 & $1-1$ & 180. \\
1 & 0. & HIST1 & Min & 0. & -97.79 & 0. & 0. & 0. & $-6.690 \times 10^{-12}$ & $1-1$ & 0. \\
1 & 90. & HIST1 & Min & 0. & -97.79 & 0. & 0. & 0. & -8792.38 & $1-1$ & 90. \\
1 & 180. & HIST1 & Min & 0. & -97.79 & 0. & 0. & 0. & -17584.76 & $1-1$ & 180. \\
2 & 0. & HIST1 & Max & 0. & 97.69 & 0. & 0. & 0. & $6.690 \times 10^{-12}$ & $2-1$ & 0. \\
2 & 90. & HIST1 & Max & 0. & 97.69 & 0. & 0. & 0. & 8800.75 & $2-1$ & 90. \\
2 & 180. & HIST1 & Max & 0. & 97.69 & 0. & 0. & 0. & 17601.5 & $2-1$ & 180. \\
\hline
\end{tabular}




\begin{tabular}{cccccccccccc}
\hline Frame & $\begin{array}{c}\text { Station } \\
\text { in }\end{array}$ & $\begin{array}{c}\text { Output } \\
\text { Case }\end{array}$ & $\begin{array}{c}\text { Step } \\
\text { Type }\end{array}$ & $\begin{array}{c}\mathbf{P} \\
\mathbf{L b}\end{array}$ & $\begin{array}{c}\text { V2 } \\
\text { Lb }\end{array}$ & $\begin{array}{c}\text { V3 } \\
\text { Lb }\end{array}$ & T & $\begin{array}{c}\text { M2 } \\
\text { Lb-in }\end{array}$ & $\begin{array}{c}\text { M3 } \\
\text { Lb-in }\end{array}$ & $\begin{array}{c}\text { Frame } \\
\text { Elemen }\end{array}$ & $\begin{array}{c}\text { Elem } \\
\text { Station } \\
\text { in }\end{array}$ \\
\hline 2 & 0. & HIST1 & Min & 0. & -97.79 & 0. & 0. & 0. & $-6.684 \times 10^{-12}$ & $2-1$ & 0. \\
2 & 90. & HIST1 & Min & 0. & -97.79 & 0. & 0. & 0. & -8792.38 & $2-1$ & 90. \\
2 & 180. & HIST1 & Min & 0. & -97.79 & 0. & 0. & 0. & -17584.76 & $2-1$ & 180. \\
3 & 0. & HIST1 & Max & 97.79 & 293.08 & 0. & 0. & 0. & 17584.76 & $3-1$ & 0. \\
3 & 24. & HIST1 & Max & 97.79 & 293.08 & 0. & 0. & 0. & 10550.85 & $3-1$ & 24. \\
3 & 48. & HIST1 & Max & 97.79 & 293.08 & 0. & 0. & 0. & 3516.95 & $3-1$ & 48. \\
3 & 72. & HIST1 & Max & 97.79 & 293.08 & 0. & 0. & 0. & 3520.3 & $3-1$ & 72. \\
3 & 96. & HIST1 & Max & 97.79 & 293.08 & 0. & 0. & 0. & 10560.9 & $3-1$ & 96. \\
3 & 120. & HIST1 & Max & 97.79 & 293.08 & 0. & 0. & 0. & 17601.5 & $3-1$ & 120. \\
3 & 0. & HIST1 & Min & -97.69 & -293.36 & 0. & 0. & 0. & -17601.5 & $3-1$ & 0. \\
3 & 24. & HIST1 & Min & -97.69 & -293.36 & 0. & 0. & 0. & -10560.9 & $3-1$ & 24. \\
3 & 48. & HIST1 & Min & -97.69 & -293.36 & 0. & 0. & 0. & -3520.3 & $3-1$ & 48. \\
3 & 72. & HIST1 & Min & -97.69 & -293.36 & 0. & 0. & 0. & -3516.95 & $3-1$ & 72. \\
3 & 96. & HIST1 & Min & -97.69 & -293.36 & 0. & 0. & 0. & -10550.85 & $3-1$ & 96. \\
3 & 120. & HIST1 & Min & -97.69 & -293.36 & 0. & 0. & 0. & -17584.76 & $3-1$ & 120. \\
\hline
\end{tabular}

Sebagai ilustrasi diambil fungsi perpindahan pada titik 2 seperti yang ditampilkan pada Gambar 4 sebagai berikut:

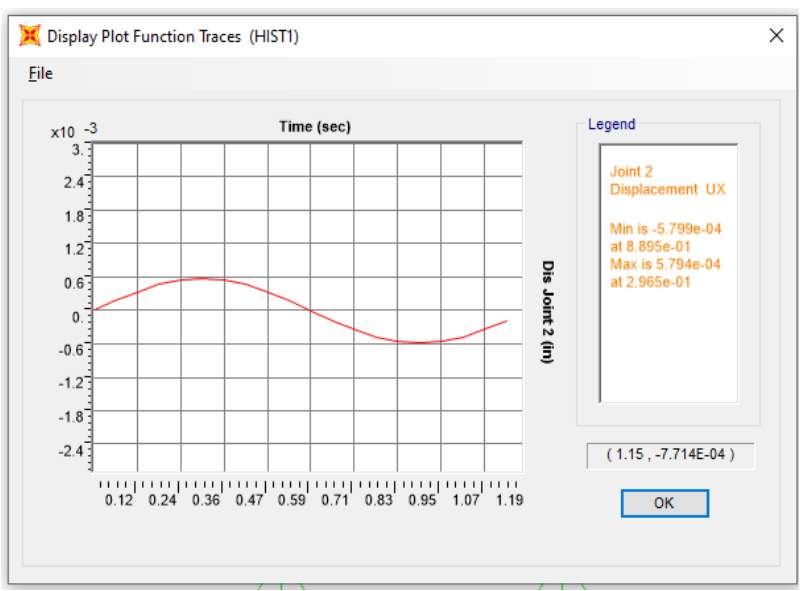

Gambar 4. Tampilan plot Function Traces (HIST1)

Rangka baja pada Gambar 3, sekarang mengalami akselerasi yang diberikan dalam fungsi $\mathrm{F}(\mathrm{t})=0,3 \sin 5,3 \mathrm{t}$. Untuk kasus ini digunakan SAP 2000 untuk menganalisis respon yang terjadi. Struktur ini dimodelkan untuk analisis secara dinamik dengan osilator teredam, dan datanya diberikan sebagai berikut:

- Spring Constant $k=2136(\mathrm{lb} / \mathrm{in})$

- Mass $m=38.86\left(l b \cdot \frac{\sec ^{2}}{i n}\right)$

- Damping $\xi=0.05$

- Amplitude Harmonic $F_{0}=200(l b)$

- Harmonic Function $F_{t}=\sin 5.3 t$

- Period : $5.3 \mathrm{t}=2 \pi, T=1.1855 \mathrm{sec}$

- Time Step: $\Delta t=\frac{T}{20}=0.059275 \mathrm{sec}$

Tabel 4. Joint displacements

\begin{tabular}{cccccccccc}
\hline Joint & OutputCase & CaseType & StepType & $\begin{array}{c}\text { U1 } \\
\text { in }\end{array}$ & $\begin{array}{c}\text { U2 } \\
\text { in }\end{array}$ & $\begin{array}{c}\text { U3 } \\
\text { in }\end{array}$ & $\begin{array}{c}\text { R1 } \\
\text { Radian }\end{array}$ & $\begin{array}{c}\text { R2 } \\
\text { Radian }\end{array}$ & $\begin{array}{c}\text { R3 } \\
\text { Radian }\end{array}$ \\
\hline 1 & ACASE1 & LinModHist & Max & 0,0000 & 0,0000 & 0,000000 & 0,000000 & 0,000000 & 0,000000 \\
1 & ACASE1 & LinModHist & Min & 0,0000 & 0,0000 & 0,000000 & 0,000000 & 0,000000 & 0,000000 \\
2 & ACASE1 & LinModHist & Max & 0,0000 & 0,0000 & 0,000000 & 0,000000 & 0,000000 & 0,000000 \\
2 & ACASE1 & LinModHist & Min & 0,0000 & 0,0000 & 0,000000 & 0,000000 & 0,000000 & 0,000000 \\
3 & ACASE1 & LinModHist & Max & 0,0000 & 0,0000 & 0,000000 & 0,000000 & 0,000000 & 0,000000 \\
3 & ACASE1 & LinModHist & Min & 0,0000 & 0,0000 & 0,000000 & 0,000000 & 0,000000 & 0,000000 \\
4 & ACASE1 & LinModHist & Max & 0,0000 & 0,0000 & 0,000000 & 0,000000 & 0,000000 & 0,000000 \\
4 & ACASE1 & LinModHist & Min & 0,0000 & 0,0000 & 0,000000 & 0,000000 & 0,000000 & 0,000000 \\
\hline
\end{tabular}


Tabel 5. Joint reaction

\begin{tabular}{cccccccccc}
\hline \multirow{2}{*}{ Joint } & OutputCase & CaseType & StepType & $\begin{array}{c}\text { F1 } \\
\text { Lb }\end{array}$ & $\begin{array}{c}\text { F2 } \\
\text { Lb }\end{array}$ & $\begin{array}{c}\text { F3 } \\
\text { Lb }\end{array}$ & $\begin{array}{c}\text { M1 } \\
\text { Lb-in }\end{array}$ & $\begin{array}{c}\text { M2 } \\
\text { Lb-in }\end{array}$ & $\begin{array}{c}\text { M3 } \\
\text { Lb-in }\end{array}$ \\
\hline 1 & ACASE1 & LinModHist & Max & 0,30 & 0,00 & 168,68 & 0,00 & 0,00 & 0,00 \\
1 & ACASE1 & LinModHist & Min & $-0,30$ & 0,00 & $-168,64$ & 0,00 & 0,00 & 0,00 \\
3 & ACASE1 & LinModHist & Max & 0,00 & 0,00 & 168,68 & 0,00 & 0,00 & 0,00 \\
3 & ACASE1 & LinModHist & Min & 0,00 & 0,00 & $-168,64$ & 0,00 & 0,00 & 0,00 \\
\hline
\end{tabular}

Tabel 4 dan 5 menunjukkan perpindahan titik dan gaya reaksi yang terjadi pada struktur portal. Kedua table tersebut adalah hasil yang diperoleh dari analisa SAP 2000.

\section{Kesimpulan}

Dari hasil analisis dengan SAP 2000, disimpulkan bahwa perpindahan hanya terjadi pada titik 2 dan titik 4, kemudian gaya aksial hanya terjadi pada batang 3 dimana aksi sebagai fungsi waktu terjadi pada titik 2 . Untuk gaya geser hanya terjadi pada arah horizontal pada batang 1, 2 dan 3. Untuk gaya reaksi hanya terjadi di titik 1 dan 3 baik pada kondisi awal maupun saat kondisi dinamik. Gaya sebagai fungsi waktu memberi pengaruh signifikan terhadap perpindahan dan gayagaya batang yang terjadi pada struktur portal.

\section{Referensi}

[1] Muis Alie M Z, Icon Yan Franchover O, Achmad Yasir B, Rachman T and Juswan 2018 Comparative Study of Structural Geometric to the Ultimate Strength on Fixed Jacket Platform MATEC Web Conf. 17701007.

[2] Muis Alie M Z 2016 The Effect of Symmetrical and Asymmetrical Configuration Shapes on Buckling and Fatigue Strength Analysis of Fixed Offshore Platforms Int. J. Technol. 71107.

[3] Aeran A, Siriwardane S C, Mikkelsen O and Langen I 2017 A framework to assess structural integrity of ageing offshore jacket structures for life extension Mar. Struct. 56 237-59.

[4] Páez P M and Sensale B 2017 Analysis of guyed masts by the stability functions based on the Timoshenko beam-column Eng. Struct. 152597 606.

[5] Shi H and Salim H 2015 Geometric nonlinear static and dynamic analysis of guyed towers using fully nonlinear element formulations Eng. Struct. 99 492-501.

[6] Tian X, Wang Q, Liu G, Liu Y and Xie Y 2019 Topology optimization design for o ff shore platform jacket structure Appl. Ocean Res. 8438 50.

[7] Vaz M A, Cyrino J C R, Hernández I D, Zegarra V D, Martinez J L and Liang D A 2018 Experimental and numerical analyses of the ultimate compressive strength of perforated offshore tubular members Mar. Struct. 58 1-17. 